\title{
АКТУАЛЬНЫЕ ВОПРОСЫ ВОСПРОИЗВОДСТВА НЕМАТЕРИАЛЬНОГО КАПИТАЛА НА РЫНКЕ ТРУДА: РЕГИОНАЛЬНЫЙ АСПЕКТ
}

\author{
(c) 2020 Шафигуллин Искандер Ильдарович \\ руководитель проектов компании McKinsey\&Company \\ E-mail: isk.shafigullin@gmail.com
}

(c) 2020 Грудина Светлана Игоревна

кандидат экономических наук, доцент кафедры управления корпоративными финансами

Института управления, экономики и финансов

Казанский (Приволжский) федеральный университет, Россия, Казань

E-mail: switki@yandex.ru

(C) 2020 Халиков Артем Ленарович

ассистент кафедры управления человеческими ресурсами

Казанский (Приволжский) федеральный университет, Россия, Казань

E-mail: artkzn16@gmail.com

В статье исследован нематериальный капитал, воспроизводимый на рынке труда региона. Нематериальный капитал трактуется авторами как уникальный, не возобновляемый ресурс, воспроизводимый человеком в процессе осознанной, творческой деятельности. Однако, не смотря на обилие исследований капитала как экономического явления, в настоящий момент наблюдается отсутствие всестороннего анализа актуальных вопросов воспроизводства нематериального капитала, который является предметом нашего исследования. Объектом исследования выступают социальноэкономические отношения, возникающие на рынке труда в процессе воспроизводства нематериального капитала. Авторские исследования развивают теорию воспроизводства нематериального капитала на рынке труда региона.

Ключевые слова: Нематериальный капитал, рынок труда, занятость, безработица, человеческий капитал, освобожденный труд, региональные социально-экономические системы.

Вопросам изучения сфер воспроизводства нематериального капитала посвящено большое количество российских и зарубежных исследований. В результате симультанного анализа ситуации на рынке труда, выполненного на базе данных Росстата, численность рабочей силы на конец 2019 года составила 76,2 млн. человек и классифицировалась по структурным направлениям [1]. Исследуя актуальные вопросы воспроизводства нематериального капитала на рынке труда в региональном аспекте, необходимо отметить, в первую очередь тот факт, что рынок труда является одним из самых быстрореагирующих рынков на изменения, происходящие в социально-экономических системах. Так, уровень регистрируемой безработицы по регионам достигает 0,9\% на конец 2018 года [2]. В региональном аспекте показатели воспроизводства нематериального капитала весьма неоднородны и существенно различаются. Распределение внедрения инноваций и интеллектуального ка- питала (в форме защиты кандидатских и докторских диссертаций) в региональном аспекте представлено на рисунке 1 .

Исходя из данных, представленных на рисунке 1 нами сделан вывод о том, что для активизации воспроизводства нематериального капитала в региональном аспекте необходимо активное, комплексное преобразование существующей модели занятости и внесение актуальных дополнений в существующие стереотипы восприятия труда и занятости как социальноэкономических явлений. Поэтапное внедрение в региональные социально-экономические системы элементов инновационного механизма занятости открывает перспективы нового качества воспроизводства нематериального капитала. И здесь мы можем говорить о новом качестве труда, развивая теорию отчужденного труда К. Маркса [3].

Новый механизм занятости и социальноэкономическая политика занятости в регио- 


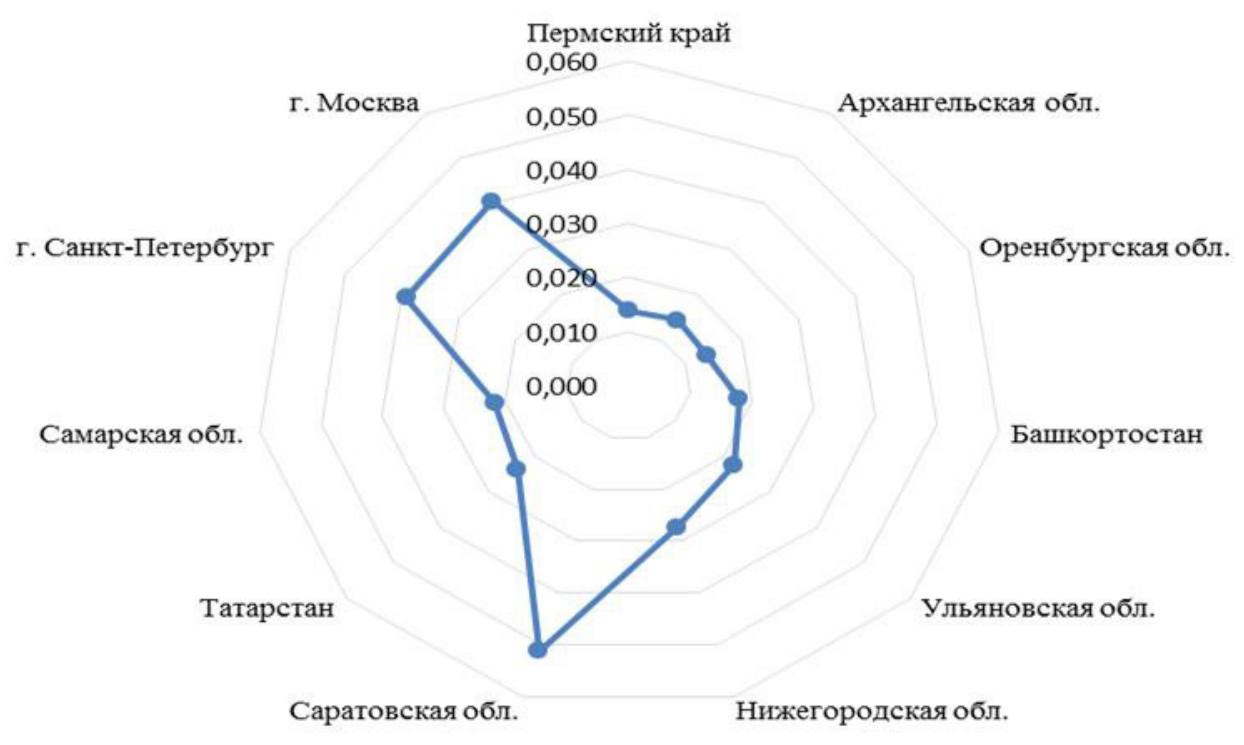

Puc. 1. Распределение внедрения инноваций и интеллектуального капитала (в форме защиты кандидатских и докторских диссертаций по регионам РФ). Источник: Разработано автором

нальном аспекте открывают перспективы для реализации труда «освобожденному». Отдельной частью нами выделен труд «освобожденный», как критерий и условие расширенного воспроизводства нематериального капитала. Уточним, что под освобожденным трудом нами понимается труд творчески активного работника, вовлечённого не отчужденно в производственный процесс создания уникального продукта, использующего свои личностные данные для производства общественно значимого продукта и продукта, особо значимого в данном регионе, воспроизводстве ограниченных благ и услуг. Труд освобождённый является антиподом труду отчужденному. Новая трактовка труда была получена в результате научного исследования посредством всестороннего переосмысления концепции К.Маркса об отчужденном труде [4]. Внедрение ее в методологию оценки воспроизводства нематериального капитала вносит существенный вклад в развитие теории воспроизводства нематериального капитала на всех уровнях хозяйствования.

Система Интернет открыла новую эпоху в организации социально-экономических отношений, отразившихся на развитии многоаспектности развития социально-экономических систем. Как и любое преобразование, трансформация рынка труда имеет свои положительные и перспективные зоны развития. Новые вызовы эпохи «освобожденного труда» открывают возможности переосмысления форм и качеств труда как фактора производства, материального ресурса и раскрытия потенциала современной занятости, что также включает в себя совершенствованную форму дистанционного управления с развитием спектра гарантий социальной направленности и перспективами востребованности уникальных способностей человека. Всесторонний анализ перспектив инновационных форм занятости и воспроизводства нематериального капитала в региональном аспекте открывает уникальные возможности экономии от масштаба, экономии от дистанционного управления воспроизводственным процессом. Но это еще не все перспективы. Особенностью новых форм воспроизводства нематериального капитала является получение доступа к уникальной интеллектуальной ренте, масштабируемой работодателем при определенных условиях хозяйствования, так называемый «А-фактор». Позитивные тренды дистанционное управление воспроизводством нематериального капитала отражает рост производительности труда, труда освобожденного. Исходя из вышеизложенного, можно сделать вывод о необходимости пересмотра региональной кадровой политики в области оценки и воспроизводства уникального нематериального капитала региона.

Анализируя предпосылки описанных выше преобразований и социально-экономических трансформаций, явившихся инновационным 
триггером - является парадигма развития сети Интернет, изменившей реальность, прошедшей через точку невозврата. Исходя из описанных позиций возможна реализация сценариев: развития, деградации, симультанной трансформации. Каждый регион проходит свой уникальный путь трансформации, лакмусом успешности которого выступает рынок труда, первый воспринимающий и отражающий социально-экономическую нестабильность и флуктуацию социально-экономических систем в депрессивном-кризисном или восстановительном развитии.

Сценарий трансформационного развития предполагает разработку политики и социальноэкономической поддержи инновационных посредников, первых ощутивших и оценивших перспективы тренда воспроизводства нематериального капитала и обозначивших пути снижения издержек материального и нематериального производства. Стадия неопределенности и выбора сценария развития провоцирует хаотические, неуправляемые импульсы социальноэкономических преобразованиях. В описанных условиях наличие порядка первого, второго и последующего уровней хозяйствования уже является ценностью, гарантией безопасности хозяйственной деятельности, что не может не отразиться на положительной оценки репутации региона. При всём богатстве научного наследия, не пройден выбор соответствующего клише или известного макроэкономический сценария развития: от кризиса, депрессии до оживления и подъёма валового регионального продукта. Следует отметить, что увеличение предложения на нематериальное производства на рынке формируют, во многом молодые участники рынка труда, конвертирующие свой нематериальный талант.

Важно отметить, инновационный механизм воспроизводства нематериального капитала создает благоприятные условия для сокращения управленческих издержек. Организация получает гибкость в воспроизводстве нематериального капитала, созданного работниками. Специфической особенностью «освобожденного труда», как формы занятости или работы временной занятости - являются неопределенные гарантии, картина «гарантированного будущего» - отсутствует.

В региональном аспекте воспроизводства нематериального капитала перспективной яв- ляется политика поддержки «самозанятых» или, другими словами - развитие теории и практики налога на профессиональный доход.

В современной научной дискуссии имеются мнения, что снижение налога на профессиональный доход до 1 процента станет мощным импульсом к не только к расширенному воспроизводству нематериального капитала, но и создаст благоприятную среду, социальноэкономический климат для активизации ресурсов человеческого потенциала, их капитализации и вовлечения в народнохозяйственный оборот.

Согласно классической теории капитала, капитал стремится в ту среду, где созданы максимально способствующие его воспроизводству условия. В настоящий момент, налог на профессиональный доход по регионам различен, но находится в диапазоне от 4 до 6 процентов (без учета индивидуальных форм субсидирования). «Самозанятые» имеют возможность регистрировать свою деятельность любом из регионов в соответствии с территориальной принадлежностью. Из этого вытекает развитие конкурентных отношений по привлечению в регион талантливых, активных членов общество, способных конвертировать таланты в капитал и делать это легитимно. Значительная часть материальных ресурсов сохраняется в региональном бюджете, может быть направлена на создание инфраструктуры воспроизводства нематериального капитала региона.

Налог на профессиональный доход выступает мощным стимулятором легитимности труда, создает возможность популяризации уникальных ремесел, форм занятости, что уже является ответом вызову времени - новой эпохи Интернет, цифровой экономики, где скрывать экономические интеракции становится технически все сложнее. Взвесив риски, связанные с нововведением, выбор большинства уникальных специалистов был сделан в пользу регистрации себя легитимно в статусе самозанятого. Следует отметить, что изначально, на стадии внедрения, налог на профессиональный доход вызывал ряд противоречивых оценок и прогнозов. Но практика показала иной результат: работать в теневом секторе экономики, скрывая свой доход, оказалось менее перспективным, чем открыто декларировать доходы.

На основе проведенного анализа актуальных вопросов воспроизводства нематериально- 
го капитала на рынке труда можно дополнить классификацию рабочей силы новой составляющей, названной в авторском исследовании как категория уникальных специалистов и соответствующей стратегии карьерных достижений и постижений. Актуальные стратегии воспроизводства нематериального капитала на рынке труда представлены в таблице 1.

Представленные в таблице 1 актуальные стратегии воспроизводства нематериального капитала на рынке труда, исходя из результатов проведенного нами исследования, являются наиболее часто встречающимися в современных условиях трансформации социально-экономических систем, цифровизации экономики, развития рынка труда. Деятельность уникального специалиста сама создает спрос на рынке труда, соответствуя закону Сея «предложение создает собственный спрос», но, в отличие от описанного классиком экономической теории мыслителя объема информации - спрос и предложения уникальны, не массовы. Противоречие уникального и массового содержит в себе ядро ответа на вопрос о будущем трансформации социально-экономических систем.

Рассмотрим подробнее участие уникальных специалистов воспроизводстве нематериального капитала и перспективность такой карьерной стратегии. Уникальность специалиста заключается в возможности работы как системно, так и индивидуально - «освобожденно», на основании собственной стратегии и уникального карьерного плана. Уникальный специалист выступает в качестве своеобразного монополиста на рынке труда, предлагающий уникальный продукт, на который, соответственно, имеется спрос и объявлена стоимость, ценность и полезность. Противоречие теории о продуцирующих и менеджерах, когда в одном человеке редко могут эффективно совмещаться талант продавать и талан создавать, безболезненно нивелируется благодаря возможности максимально освободиться от бюрократических, финансовых, отчетных барьеров и сосредоточится на продуцировании, создания нового уникального продукта при минимальных издержках получив статус самозанятого, платя налог на профессиональный доход.

В продолжении исследования проанализируем перспективу внесения субсидирования уникальности для специалистов воспроизводящих востребованный и пользующийся спросом уникальный продукт. И сделать это рекомендуется путем разработки механизма индивидуального снижения налога на профессиональный налог в общественно и социально востребованных на настоящий момент областях развития социально-экономической, культурной, экологической деятельности в конкретном регионе.

Индивидуальный подход к налогообложению каждого конкретного специалиста и его виду деятельности открывает перспективу поддержки уникальности и «выхода из тени» по настоящему значимых форм предпринимательской деятельности. Индивидуальный подход, в целом, только начинает разрабатываться и некоторые результаты такого подхода уже проявились в условиях поддержки самозанятых в условиях пандемии короновируса Ковид-19.

Пандемия короновируса обострила и проявила уже сформированный слой вопросов, связанных с индивидуальным предпринимательством и самозанятостью, когда контакты «человекчеловек» стали ограниченными и активизиро-

Таблица 1. Стратегии воспроизводства нематериального капитала на рынке труда

\begin{tabular}{|c|l|l|}
\hline № & Наименование стратегии & \multicolumn{1}{|c|}{ Краткое описание стратегии } \\
\hline 1. & Следование за лидером & $\begin{array}{l}\text { Стратегия заключается в минимизации издержек за счет следования } \\
\text { за лидером, задающим тренд на рынке труда. Минимизация риска не- } \\
\text { определенности является достоинством данной стратегии. Недостаток } \\
\text { заключается в невозможности получения сверхприбыли, ограничен- } \\
\text { ное воспроизводство нематериального капитала. }\end{array}$ \\
\hline 2. & Адаптационная & $\begin{array}{l}\text { Стратегия адаптационная или «избегания неудач» на рынке труда } \\
\text { может быть использована в период неопределенности и социально- } \\
\text { экономической трансформации рынка труда. }\end{array}$ \\
\hline 3. & Уникальный специалист & $\begin{array}{l}\text { Стратегия максимального риска и максимальной прибыли. Стратегия } \\
\text { является ответом на трансформацию и развития рынка труда. Досто- } \\
\text { инством стратегии является качественное и расширенное воспро- } \\
\text { изводство нематериального капитала в региональной социально- } \\
\text { экономической системе. }\end{array}$ \\
\hline
\end{tabular}

Источник: разработано автором. 
вались взаимодействия «человек - компьютерная технология». Невозможность личных встреч и взаимодействий между людьми вынужденно перевела все бизнес и частные взаимодействия в интернет-пространство. А интернет пространство отличается обладает признаками прозрачности и мгновенного определения уникального от тиражированного (простой пример - система поиска заимствований в текстах, распознавания лиц так далее).

На основании проведенного исследования актуальных вопросов воспроизводства нематериального капитала, можно сделать вывод о том, что человек на рынке труда в современных условиях нарастающей цифровизации и развития системы интернет, конкурирует и не всегда выигрывает в конкуренции с компьютерными мощностями, цифровыми помощниками и технологиями, робототехникой и тому подобными инновациями. Рынок труда также отреагировал повышенным спросом на уникальных специалистов, истинных мастеров уникального производства, являющихся драйверами преобразований и формирования базиса устойчивого развития.
Следовательно, возникает сложность координации многих изменчивых переменных на рынке труда, сохранения факторов устойчивости, порядка и баланса спроса и предложения на рынке труда в условиях воспроизводства нематериального капитала оставляют открытыми многие вопросы выбора пути развития не только экономики отдельно взятого региона, но человечества в целом. Все вышеизложенное показывает необходимость дальнейших исследований воспроизводства нематериального капитала, носителем которого является человек, его уникальные способности и навыки. Уникальная среда региона и присущая ему региональная социально-экономическая система способствуют либо расширенному воспроизводству нематериального капитала, либо его деградации. Необходим комплекс мероприятий по поддержке уникальных инициатив ученых, предпринимателей, рискнувших принять активное участие в построении новых региональных социальноэкономических систем трансформирующего рынка труда, поскольку именно рынок труда является главным индикатором происходящих процессов в социально-экономической системе региона.

\section{Библиографический список}

1. Федеральная служба государственной статистики: «Рабочая сила, занятость и безработица в России» 2019 г.

2. Министерство труда и социальной защиты Российской федерации. Официальный сайт.

3. Маркс К. Экономическо-философские рукописи 1844 г. // Соч. 2-е изд. М.: Политиздат, 1974. Т. 42. С. $41-174$.

4. Нарский И. С. Отчуждение и труд: по страницам произведений К. Маркса. М.: Мысль, 1983. 144 с.

5. Богдашев И.В., Адаменко А. А., К вопросу об интеллектуальной элите, журнал «Экономика и предпринимательство», № 11, 2013 г.

6. Богдашев И.В., Интеллект и интеллектуальная элита в экономике знаний, Journal of Economy and entrepreneurship, Vol. 8, Nom. 1-2

7. Грудина С.И. Современная парадигма эффективности инновационной деятельности и конкурентоспособность российских предприятий // Актуальные проблемы экономики и права. - 2012. - № 2.-C.27-28.

8. Грудина С.И. Рынок труда в условиях глобализации и международная конкурентоспособность// Актуальные проблемы экономики и права. - 2011.- № 3.- С.14-15.

9. Маркс К. Капитал.-М.: Лениздат, 2001,-Т.1.-512с.

10. Фахрутдинова Е.В., Колесникова Ю.С. Концентрация нематериальной собственности нематериальных активов в РФ и в мире: сравнительная характеристика// Вестник Самарского государственного экономического университета. - 2017. - № 8 (154).- С. 36-42.

11. Фахрутдинова Е.В., Колесникова Ю.С. Эволюция категории «нематериальная собственность»// Экономические науки. - 2014. - № 117.- С. 41-46.

12. Фахрутдинова Е.В., Рынок труда в России и динамика его потребностей // Экономические науки. - 2014.№ $110 .-$ C.43-46.

13. Ягупа Е.Г. Виды, характеристика и современное состояние нематериального капитала региона // Креативная экономика. - 2011.- Том 5.- № 11.- С. 17-23.

14. Loseva, O. V. Methods for Measuring of Regional Intellectual Capital / Loseva O.V., Fedotova M.A., Filimonova N. M. // Information. - Volume 19, Number 6 (A), 2016, Tokyo, Japan. - 1771-1785 № 6 (A) - 2016 